Binghamton University

The Open Repository @ Binghamton (The ORB)

Summer 2014

\title{
Preparing Public Service Professionals for a Diverse and Changing Workforce and Citizenry: Evaluating the Progress of NASPAA Programs in Competency Assessment
}

\author{
Nadia Rubaii \\ Binghamton University--SUNY, nadia.rubaii@binghamton.edu \\ Crystal Calarusse \\ NASPAA
}

Follow this and additional works at: https://orb.binghamton.edu/public_admin_fac

Part of the Public Administration Commons

\section{Recommended Citation}

Rubaii, N., \& Calarusse, C. (2014). Preparing Public Service Professionals for a Diverse and Changing Workforce and Citizenry: Evaluating the Progress of NASPAA Programs in Competency Assessment. Journal of Public Affairs Education,20(3). 285-304.

This Article is brought to you for free and open access by the Public Administration at The Open Repository @ Binghamton (The ORB). It has been accepted for inclusion in Public Administration Faculty Scholarship by an authorized administrator of The Open Repository @ Binghamton (The ORB). For more information, please contact ORB@binghamton.edu. 


\title{
Preparing Public Service Professionals for a Diverse and Changing Workforce and Citizenry: Evaluating the Progress of NASPAA Programs in Competency Assessment
}

\author{
Nadia Rubaii \\ Binghamton University
}

Crystal Calarusse

NASPAA

\begin{abstract}
This paper examines the self-reported progress of public service degree programs in NASPAA for defining, measuring, and assessing student learning outcomes as they relate to the "ability to communicate and interact productively with a diverse and changing workforce." The analysis is placed in the context of the need for cultural competencies among public administration professionals and the evolution of this accreditation standard. Using data drawn from accreditation records, we first present an exploratory qualitative analysis of how programs are defining this competency over time and how progress on this competency relates to progress on competency assessment generally and to other measures of program diversity. We interpret all findings in the context of two broad goals: to provide an accurate assessment of program progress and to provide useful information to programs seeking to develop their competency definitions and assessment.
\end{abstract}

\section{KEYWORDS}

cultural competence, assessment, accreditation

At the October 2009 NASPAA annual conference, NASPAA-accredited programs overwhelmingly approved a new set of accreditation standards that maintained the existing framework of mission-based accreditation while implementing important changes in criteria for assessment of program quality. NASPAA expanded its accreditation to programs outside the United States, required that programs more explicitly articulate the public service values considered most important in the context of each program's mission, and, most notably for the purposes of this paper, placed a much greater emphasis on student learning outcomes as a central feature of the accreditation review. This transition to what has been labeled a third generation of accreditation standards (Rubaii \& Calarusse, 2012), with its increased attention to student learning outcomes, reflects changes occurring throughout higher education both in the United States and globally in response to pressure for greater accountability to stakeholders.

NASPAA accreditation addresses student learning outcomes_or what are commonly 
referred to as competencies when discussed in the context of professional master's degree programs-within Standard 5, "Matching Operations with the Mission: Student Learning," which states, in part, that all programs shall ensure that graduates can do all of the following:

1. Lead and manage in public governance.

2. Participate in and contribute to the public policy process.

3. Analyze, synthesize, think critically, solve problems, and make decisions.

4. Apply a public service perspective.

5. Communicate and interact productively with a diverse and changing workforce and citizenry.

Collectively, these five areas are referred to as the Universal Competencies (UCs). Programs seeking NASPAA accreditation are required to (a) define each of the universal competencies within the context of their own mission and public service values, (b) develop measures and gather data on each competency, (c) analyze the data systematically, and (d) use the results of the analysis to inform programmatic improvements. This four-step process constitutes a full assessment cycle.

Between the initial pilot year of standards implementation (2011-12) and this analysis, expectations for conformance to student learning assessment have been phased in gradually, in an effort to ensure a reasonable pace of implementation. Eventually, the expectation will be that programs seeking accreditation will have fully assessed all five UCs and that they will continue to do so on a regular basis. In their Self-Study Reports, programs are required to indicate how far along in the assessment process they are for each of the universal competencies. However, to streamline the reporting requirements, programs need only document and provide a detailed account of the full assessment cycle for one UC as part of the Self-Study Report. The competencies chosen by programs to highlight in this report provide insight into assessment progress in the five competency areas.
The focus of this paper is primarily on the fifth competency-"to communicate and interact productively with a diverse and changing workforce and citizenry," hereafter referred to simply as either the "diversity competency" or simply "UC5." A NASPAA White Paper released in February 2012, which examined SelfStudy Reports from the 2010-11 pilot program $(n=6)$ and the 2011-12 cohort $(n=23)$, documented that UC5 was one of the least frequently selected competencies for reporting in the Self-Study report. Of the 29 programs under review during that period, only two programs $(<7 \%)$ reported on UC5, and one of those was a program that reported on all five of the UCs (Saint-Germain \& Powell, 2012).

In this paper, we examine how competency assessment has progressed since then. We combine a qualitative and quantitative analysis to document to what extent and in what manner NASPAA-accredited programs have defined and assessed the diversity competency as well as to examine whether progress on assessment of the diversity competency relates to other diversity factors reviewed during the accreditation process. The goals of this review are to better document progress as a profession in this important area and also to inform programs seeking to improve their competency definitions.

\section{THE RESEARCH CONTEXT}

An emphasis on assessment of student learning outcomes in higher education is part of the broader demand for accountability, performance measurement, and results in all sectors. These pressures stem from government mandates, stakeholder demands, and increased market competition. Quality assurance is particularly relevant in professional degree programs, where the lack of skilled professionals in the fields such as medicine, nursing, engineering, planning, social work, and public administration can have disastrous consequences. Accreditation is a powerful mechanism in the effort to ensure that graduates of a particular profession have the knowledge, skills, and abilities necessary for successful practice. Although neither the emphasis on competencies as part of the quality assurance review nor the concern about 
competencies related to diversity are unique to public affairs education, the nexus of public affairs and diversity competencies is of particular importance. As we prepare students for positions of responsibility and leadership in public service, it is essential that we provide them with skills to demonstrate accountability and results within their own organizations and that we model what we teach through our own systematic and thoughtful assessment processes.

The importance of cultural competency in general and within public service professions in particular is well documented. We recount it only briefly here, given our greater focus on assessment progress as opposed to cultural competency per se. Because graduates of NASPAA programs are expected to be leaders in protecting the public interest, it is particularly important that they be "prepared to advocate for diverse populations" (White, 2004, p. 114). When culture is not adequately considered in the study or practice of public administration, clients of public services agencies and ultimately the public as a whole will likely suffer (Rice, 2007).

The growing appreciation for the importance of diversity and the increasing demands for cultural competencies are reflected in the evolution of the NASPAA accreditation requirements. Rubaii and Calarusse (2012) document how diversity has been addressed to a greater extent in each generation of the NASPAA standards; they also identify some of the anticipated challenges associated with the current requirements. Over time, programs have been expected to provide evidence of programspecific efforts to ensure diversity in the faculty and the student body, to create and maintain a climate of inclusiveness, and to address topics of diversity within their courses. With the current accreditation standards, programs are required to go further and demonstrate the competency of their students to "communicate and interact productively with a diverse and changing workforce and citizenry" and assess how well they are doing so. The capacity of programs to define and assess cultural competencies; the capacity of the Commission on Peer Review and Accreditation (COPRA) to evaluate the assessment progress through the Self-Study Report and site visit process; and whether the diversity competency would have very different manifestations in different institutional contexts, such as institutions outside of the United States or those serving large minority populations, were all identified as challenges associated with the conformity with UC5 (Rubaii \& Calarusse, 2012).

Traditional teaching about diversity has focused on ensuring knowledge of nondiscrimination laws and policies, but this knowledge alone does not constitute competence in working with diversity. Students must also be able to apply their knowledge and the values of diversity, equity, and justice to policy decisions and actions. Cultural competence in the realm of laws and policies demands that students be able to evaluate policies and procedures in terms of the four criteria identified by the National Academy of Public Administration (NAPA) of procedural fairness, distributional equity, process equity, and outcomes disparities (Norman-Major, 2011), and to recognize and respond to inequities based on traditional diversity characteristics such as gender and race as well as social class (Wyatt-Nichol, Brown, \& Haynes, 2011). Similarly, the general skills of effective communication and interpersonal relations are a starting point but more specialized communication skills are required to work effectively in diverse team and group settings and to negotiate, facilitate, or mediate among diverse interests, perspectives, and styles of individuals (Page, 2007).

Cultural competency can be thought of as a cycle that begins with knowledge and awareness and progresses to skills (Rice \& Matthews, 2012). According to this model, cultural awareness involves acceptance of the value and significance of one's own cultural heritage and of difference, and a better understanding of one's own behavior and worldview, its cultural heritage, and its impact on others. Cultural knowledge extends to learning about diverse cultures and groups, the nature of institutional power in various cultures, and the availability 
of resources to facilitate culturally appropriate referrals for services. Cultural skills bring together awareness and knowledge in the form of effective communication, respect, empathy, and trust with individuals who are different from oneself (Rice \& Matthews, 2012).

Diversity manifests itself in several interrelated ways within an organization or program. In their Cultural Competence Framework, P. Lewis, R. Lewis, and Williams (2012) portray the interrelated elements of cultural knowledge, cultural sensitivity, cultural competency, and cultural proficiency as the result of many program design elements, beginning with the program mission and governance structure. These factors influence policies and practices regarding recruitment, retention, and development of faculty and students - which in turn drive the organizational environment and inform the curriculum of the program and the teaching, research, and service activities of faculty (Lewis et al., 2012). Similarly, in describing and analyzing the experience of teaching a course in Cultural Competency and Managerial Leadership at Hamline University, Bonilla, Lindeman, and Taylor (2012) provide evidence that a climate that provides a safe space for diversity contributes to student learning and the development of cultural competencies.

NASPAA Standards reflect this idea that diversity has many facets. Programs are required to document their efforts and progress in the recruitment and retention of diverse faculty and students and in creating a climate of inclusion for all. The NASPAA Diversity Report 2013 (Primo, 2013) documents progress in NASPAA member programs between 19992000 and 2009-10 in areas of both faculty and student diversity on the basis of race and gender. In the case of student diversity, NASPAA programs have progressed at rates that exceed national averages as reported by the U.S. Department of Education's National Center for Education Statistics (U.S. Department of Education, 2012). Despite this progress, COPRA continues to identify problems requiring monitoring on the standards related to faculty and student diversity (Standards 3.2 and 4.4, respectively), at a rate higher than most other accreditation standards; $18 \%$ of programs that have sought accreditation under the 2009 Standards are currently monitored on faculty diversity (Mizrav, 2012).

\section{RESEARCH QUESTIONS}

Several research questions guide this analysis; they are grounded in both the literature and the experiences of the authors in various roles within the accreditation process. The questions are as follows:

1. How are programs defining the universal competency to "communicate and interact productively with a diverse and changing workforce and citizenry"?

2. To what extent and in what ways is progress on the assessment of the diversity competency related to other general program characteristics (such as progress in assessment of the other universal competencies, the passage of time since initial implementation, or whether the program is seeking initial accreditation or reaccreditation)?

3. To what extent and in what ways is progress on UC5 related to other aspects of diversity within a program (for example, mission references to diversity, faculty diversity, student diversity, or institutional status as a minority-serving institution)?

\section{RESEARCH METHODOLOGY}

This exploratory analysis seeks to describe the current state of progress on the assessment of NASPAA's diversity competency and to contribute to the understanding of factors that may be related to program progress. We use both qualitative and quantitative methods to examine individual variables as well as relationships of association or difference among variables. The emphasis is on understanding, but not necessarily explaining. Thus, although we examine correlations among some variables, we neither assert nor test any causal relationships. 


\section{Data Sources}

The data were drawn from Self-Study Reports (SSRs) submitted through NASPAA's online data system for programs in the 2010-11 pilot year that voluntarily used the 2009 Standards, through the 2013-14 cohort. Additional data from Site Visit Team reports was included for those programs in that period for which site visits have been completed and submitted online. Site Visit Team report data is not available at the time of writing for programs in the 2013-14 cohort or for programs in the 2012-13 cohort that delayed their site visits; one additional program from an earlier 201112 cohort is missing Site Visit Team report data because that report was not submitted online.
Data on other program characteristics were obtained from the NASPAA Data Center.

\section{Descriptive Statistics}

A total of 91 programs are included in the analysis, representing 85 universities. Most analysis includes all 91 programs; however, analysis involving Site Visit Team report data is limited to 58 programs. Among the 91 programs that have undergone accreditation review using the standards adopted in 2009, more than three quarters $(77 \%)$ have been Master of Public Administration (MPA) degrees. Much smaller proportions use the degree title called Master of Public Affairs (MPAff), Master of Public Policy (MPP), or some other name (Figure 1).

\section{FIGURE 1.}

Programs by Degree Title Seeking NASPAA Accreditation or Reaccreditation under Standards 2009 between 2010-11 and 2013-14

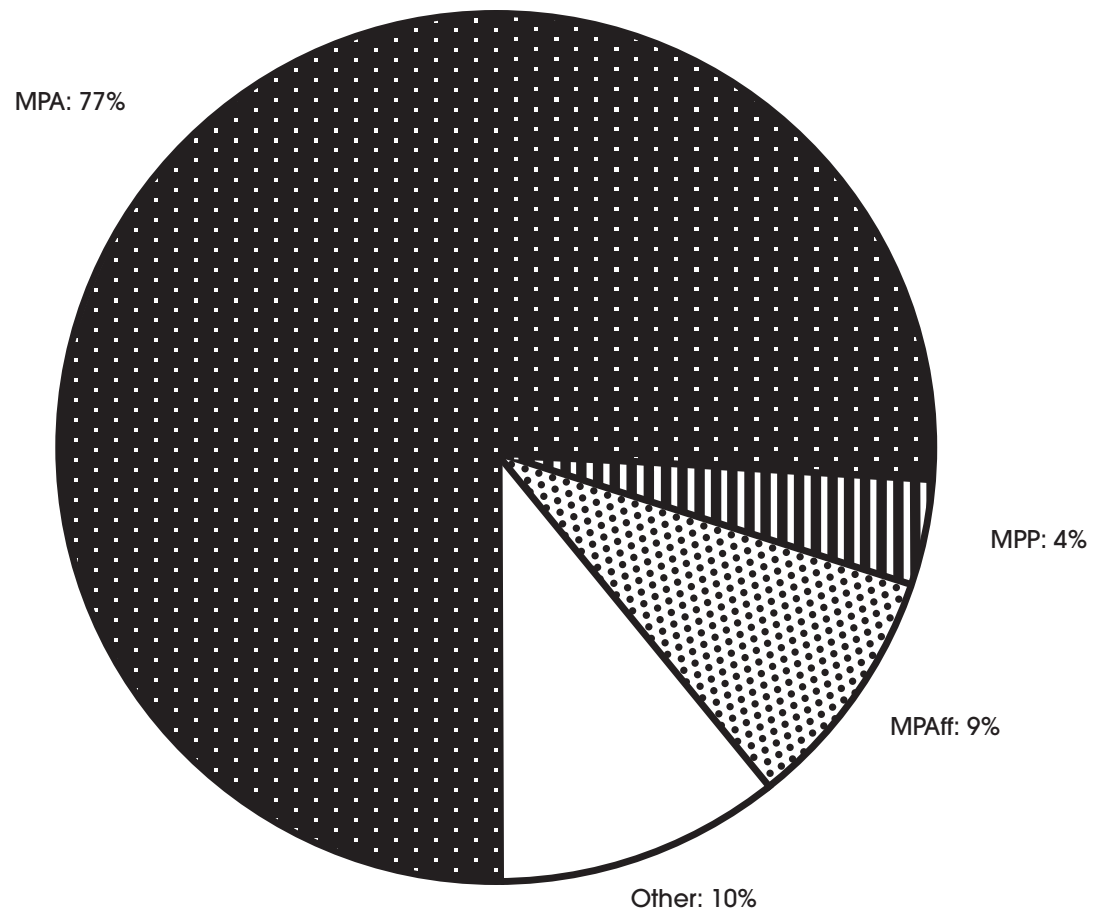




\section{FIGURE 2.}

Number of Programs Reviewed using Standards 2009 by Cohort Year \& Accreditation Status

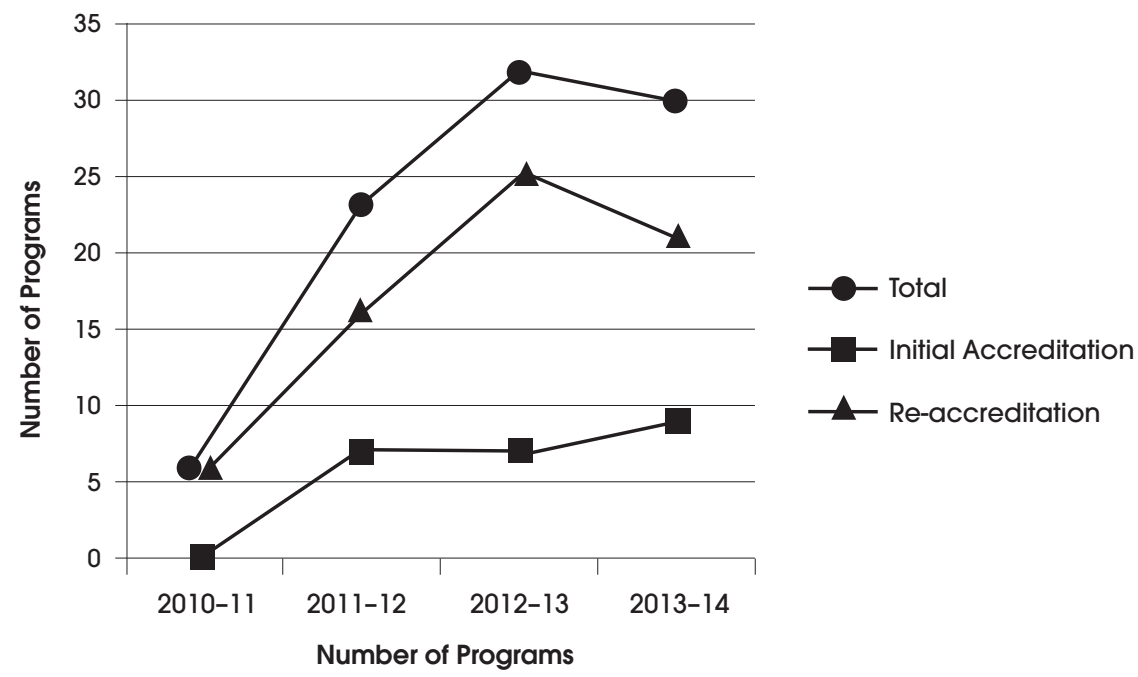

Note. $n=91$

In the pilot year (2010-11), use of the newly adopted standards was limited to a small group of volunteers, all seeking reaccreditation. In subsequent years, all programs - those seeking reaccreditation as well as those applying for initial accreditation-were required to do so. Figure 2 illustrates the composition of the programs that were seeking either initial accreditation or reaccreditation in each of the cohort years included in the analysis.

As illustrated in Figure 2, there has been a steady increase in the number of programs undergoing accreditation review by the Commission on Peer Review and Accreditation at NASPAA (COPRA) using the Standards 2009 requirements. Five to 10 new programs have entered the accreditation review cycle each year since full implementation of the standards. The small number of programs in 2010-11 is somewhat misleading; as mentioned earlier, this was a pilot year for the standards that had recently been adopted. In 2010-11, most of the programs were reviewed according to earlier standards and thus are not represented in the figure or included in our analysis. The relatively stable number of programs seeking reaccreditation in 2012-13 and 2013-14 is not due to chance, but instead reflects a deliberate effort by NASPAA to even out the workload for COPRA and avoid a disproportionate number of programs in the review cycle in 2012-13. Nine programs that had been scheduled for reaccreditation review as part of the 2012-13 cohort were placed into a "smoothing cohort" and had their official review year changed to 2013-14.

\section{ANALYSIS}

Earlier we identified three broad research questions for this paper. In this section, we describe how we approached the analysis of each of the three questions and also present the results of the analysis. An interpretation of the findings and discussion of their implications is provided later.

\section{Defining the Diversity Competency}

NASPAA standards dictate a four-step process for assessment of student learning outcomes. It begins with developing a clear conceptual and operational definition of the competency in the 
context of a program's unique mission and the public service values. Learning outcomes or competencies are "statements regarding skills, knowledge, and values or attitudes that students should possess after completing a program" (Norman-Major, 2012, p. 311). Subsequent stages of the process - data collection, data analysis, and use of the findings from the analysis to guide program improvements-are all predicated on a clearly defined competency.

As the first stage in the assessment process, the competency definitions are a logical place to begin our research. In a 2011 NASPAA white paper, programs were cautioned that it is "imperative that programs devote time and effort to identifying what the competency means for their courses and programs" (Powell, Piskulich, \& Saint-Germain, 2011, p. 2). This same report provided advice to programs on developing competency definitions, clearly articulating how the definition is related to the program mission, the manner in which the competency is embedded in the curriculum, and various measurement and assessment options. The focus of the white paper was to inform programs about how to document program decisions and processes for COPRA and the opportunities for stakeholder involvement in each stage (Powell, Piskulich, \& SaintGermain, 2011). This research builds on that earlier work by examining more closely the definitions developed by programs with respect to a specific competency.

\section{FIGURE 3.}

Number of Dimensions Included in the Definition of Universal Competency 5

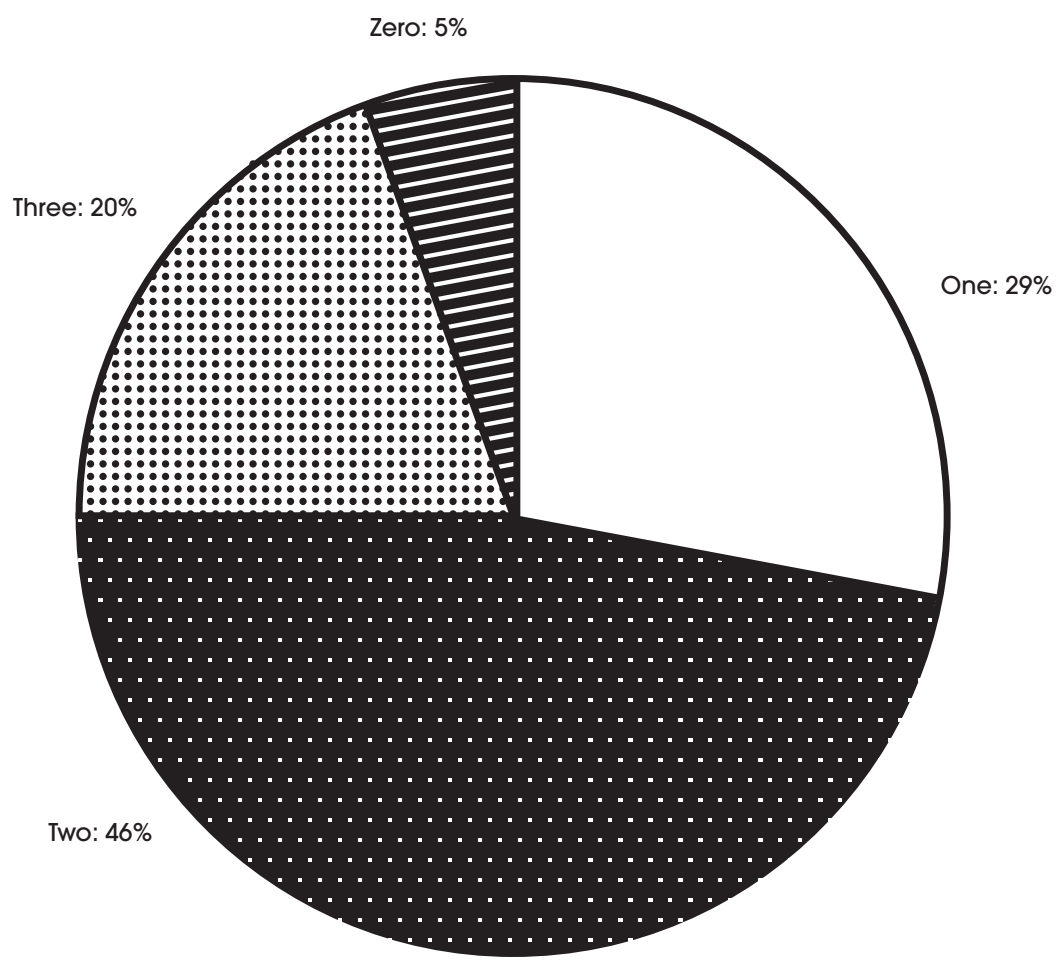


TABLE 1.

Typology of Definitions of Universal Competency 5

\begin{tabular}{|c|c|c|c|}
\hline Dimension & Omitted (0) & Knowledge or basic skills (1) & $\begin{array}{l}\text { Application of knowledge } \\
\text { or advanced skills (2) }\end{array}$ \\
\hline Communication & $\begin{array}{l}\text { No explicit } \\
\text { mention of } \\
\text { communication } \\
\text { in Competency } \\
\text { Definition }\end{array}$ & $\begin{array}{l}\text { Communication skills. Com- } \\
\text { petency Definition refers to } \\
\text { oral communication, written } \\
\text { communication, organization of } \\
\text { ideas, and tailoring communi- } \\
\text { cation to different audiences. }\end{array}$ & $\begin{array}{l}\text { Teamwork and group dynamics. } \\
\text { Competency Definition refers to } \\
\text { skills to communicate effectively } \\
\text { in group settings; to lead, follow, } \\
\text { and collaborate; to incorporate } \\
\text { diverse perspectives; to engage } \\
\text { in conflict resolution; to facilitate, } \\
\text { negotiate, or mediate; and/or } \\
\text { the ability to work with people } \\
\text { of different backgrounds and } \\
\text { beliefs and work styles. }\end{array}$ \\
\hline $\begin{array}{l}\text { Laws and } \\
\text { policies }\end{array}$ & $\begin{array}{l}\text { No explicit } \\
\text { mention of laws } \\
\text { or policies in } \\
\text { Competency } \\
\text { Definition }\end{array}$ & $\begin{array}{l}\text { Knowledge/laws/policies. Com- } \\
\text { petency Definition emphasizes } \\
\text { the importance of knowing } \\
\text { laws and policies regarding } \\
\text { nondiscrimination (EEO, AA, } \\
\text { ADA, etc.), the legal environ- } \\
\text { ment, workforce development } \\
\text { issues and values of equality, } \\
\text { social equity, or social justice. }\end{array}$ & $\begin{array}{l}\text { Implications of policy changes for } \\
\text { different stakeholders. Competen- } \\
\text { cy Definition refers to the applica- } \\
\text { tion of legal/policy knowledge. } \\
\text { This may take the form of students } \\
\text { analyzing what populations are } \\
\text { advantaged and disadvantaged } \\
\text { by various policy options, or using } \\
\text { values of diversity and social equity } \\
\text { in the design, implementation, } \\
\text { analysis, or evaluation of policy. }\end{array}$ \\
\hline Diversity & $\begin{array}{l}\text { No explicit } \\
\text { mention of } \\
\text { diversity in } \\
\text { Competency } \\
\text { Definition }\end{array}$ & $\begin{array}{l}\text { Diversity. Competency Definition } \\
\text { refers to importance of knowl- } \\
\text { edge, awareness, appreciation, } \\
\text { or sensitivity of differences asso- } \\
\text { ciated with race, gender, ethnicity, } \\
\text { religion, age, disability, language, } \\
\text { and/or socioeconomic status. }\end{array}$ & $\begin{array}{l}\text { Cultural competence. Comptency } \\
\text { Definition indicates that students } \\
\text { will demonstrate their awareness } \\
\text { and sensitivity through their ac- } \\
\text { tions and will demonstrate cultural } \\
\text { sensitivityand skills in working with } \\
\text { different values and cultures. }\end{array}$ \\
\hline
\end{tabular}

Our first research question asks: How are programs defining the universal competency to "communicate and interact productively with a diverse and changing workforce and citizenry"? To answer that question, we conducted a content analysis of the definitions of UC5 provided by programs in their Self-Study Reports as part of Standard 5 and analyzed the content using a typology we developed based on the literature on diversity and cultural competence. The typology includes three dimensions, each with three possible levels of inclusion in the program definition measured at the ordinal level. The dimensions relate to Communication, Laws and Policies, and Diversity. The levels range from no reference to the dimension in the competency definition (scored as 0), to knowledge or basic skills (1), to application of knowledge and advanced skills (2). An overview of the typology is presented in Table 1.

The typology has face validity in that it encompasses the aspects of diversity most often discussed in the literature. To ensure the interrater reliability of typology, the researchers evaluated the program definitions of UC5, applied the typology independently, and then compared their coding. Where there were differences, we discussed the basis for our interpretations and agreed on how to clarify and make more precise the criteria used for each level within each dimension. We then 
each recoded independently using the more detailed typology. We repeated this process until we had clarity in the criteria and consensus and consistency in the coding.

Nearly half (46\%) of all programs incorporate two of the typology dimensions in their definitions of the diversity competency, whereas less than one third (29\%) focus on only one dimension and one fifth (20\%) use all three dimensions (Figure 3).

The most commonly referenced dimension from the typology is the first dimension related to Communications, which was part of the competency definitions for $78 \%$ of programs $(n=71)$, followed by the Diversity dimension referenced in $65 \%$ of the definitions $(n=59)$; the Laws and Policies dimension was found in only $37 \%$ of the definitions $(n=34)$. Figure 4 depicts, on each of the dimensions, the extent to which program definitions of UC5 were at the level of knowledge or basic skills (level 1) or at the level of advanced skills or application of knowledge (level 2).

Many of the competency definitions reported by programs are drawn directly from the examples provided in Appendix B of the NASPAA Self-Study Instructions, which were developed by NASPAA Self-Study Instructions Task Force, approved by COPRA following adoption of the standards in October 2009, and then updated in 2012, 2012, and 2013. The reliance on examples from this document may at least partly explain why more programs focus on the first and third dimensions of our typology regarding Communication and Diversity, respectively, relative to the second dimension regarding Laws and Policies; this is consistent with the representation of those dimensions with the examples provided in the Self-Study Instruction document. Although the intent is to have competency definitions that are grounded in and tailored to the program mission, very few programs in this data set are doing that for UC5.

FIGURE 4.

Number of Dimensions Included in Definition of Universal Competency 5

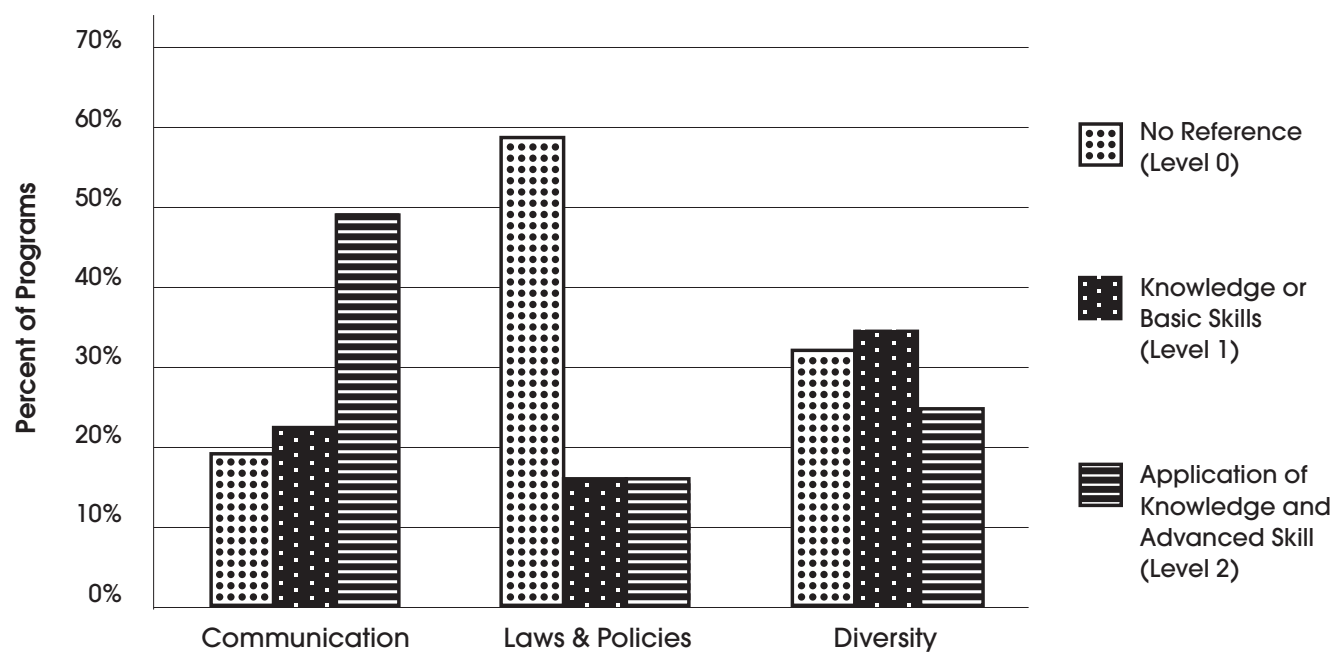




\section{Progress in Competency Assessment}

Our second research question asks: To what extent and in what ways is progress on the assessment of the Diversity competency related to other general program characteristics? Here we are interested in knowing whether the Diversity competency continues to be one of competencies least frequently selected by programs in their Self-Study Reports as well as how progress on assessing the Diversity competency compares to progress on the four other universal competencies both in absolute terms and in terms of the accuracy of self-reported progress on assessment relative to site visit team

TABLE 2.

Definitions of Key Variables for Research Question 2

\begin{tabular}{|c|c|c|c|}
\hline Concept & $\begin{array}{l}\text { Measure (level of } \\
\text { measurement) }\end{array}$ & Coding & Source \\
\hline Time & $\begin{array}{l}\text { Cohort year as deter- } \\
\text { mined by submission } \\
\text { of SSR (ordinal) }\end{array}$ & $\begin{array}{l}10=2010-11 \\
11=2011-12 \\
12=2012-13 \\
13=2013-14\end{array}$ & $\begin{array}{l}\text { NASPAA } \\
\text { Data Center }\end{array}$ \\
\hline $\begin{array}{l}\text { Accredita- } \\
\text { tion status }\end{array}$ & $\begin{array}{l}\text { Program status at the } \\
\text { time of submission } \\
\text { of SSR (nominal) }\end{array}$ & $\begin{array}{l}0=\text { initial accreditation application } \\
1=\text { reaccreditation application }\end{array}$ & $\begin{array}{l}\text { NASPAA } \\
\text { Data Center }\end{array}$ \\
\hline $\begin{array}{l}\text { Selected } \\
\text { competency }\end{array}$ & $\begin{array}{l}\text { Which of the five } \\
\text { universal competen- } \\
\text { cies the program } \\
\text { selected to report in } \\
\text { the SSR (nominal) }\end{array}$ & $\begin{aligned} 1= & \text { lead and manage in public governance } \\
2= & \text { participate in and contribute to the } \\
& \text { policy process } \\
3= & \text { analyze, synthesize, think critically, } \\
& \text { solve problems, and make decisions } \\
4= & \text { apply a public service perspective } \\
5= & \text { communicate and interact productively } \\
& \text { with a diverse and changing workforce } \\
& \text { and citizenry } \\
6= & \text { reported on more than one competency }\end{aligned}$ & $\begin{array}{l}\text { SSR, Standard } \\
\text { 5.1, Part C }\end{array}$ \\
\hline $\begin{array}{l}\text { Self-reported } \\
\text { progress on } \\
\text { assessment }\end{array}$ & $\begin{array}{l}\text { Program's report of } \\
\text { their level of assess- } \\
\text { ment on each com- } \\
\text { petency (ordinal) }\end{array}$ & $\begin{array}{l}0=\text { no action taken } \\
1=\text { competency defined } \\
2=\text { data gathered } \\
3=\text { data analyzed } \\
4=\text { results of analysis used }\end{array}$ & $\begin{array}{l}\text { SSR, Standard } \\
\text { 5.1, Part B }\end{array}$ \\
\hline $\begin{array}{l}\text { Full assess- } \\
\text { ment of all } \\
\text { universal } \\
\text { compe- } \\
\text { tencies }\end{array}$ & $\begin{array}{l}\text { Number of univer- } \\
\text { sal competencies } \\
\text { reported at level } 4 \text { of } \\
\text { assessment (interval) }\end{array}$ & $\begin{array}{l}0=\text { none of the five } \\
1=\text { any one of the five } \\
2=\text { any two } \\
3=\text { any three } \\
4=\text { any four } \\
5=\text { all five are reported at level } 4\end{array}$ & $\begin{array}{l}\text { SSR, Standard } \\
\text { 5.1, Part B }\end{array}$ \\
\hline $\begin{array}{l}\text { Site visit team } \\
\text { assessment } \\
\text { of progress }\end{array}$ & $\begin{array}{l}\text { Site visit team's } \\
\text { report of assessment } \\
\text { level on a compe- } \\
\text { tency (ordinal) }\end{array}$ & $\begin{array}{l}0=\text { no action taken } \\
1=\text { competency defined } \\
2=\text { data gathered } \\
3=\text { data analyzed } \\
4=\text { results of analysis used }\end{array}$ & $\begin{array}{l}\text { SVT Reports, } \\
\text { Standard } \\
\text { 5.1, Part B }\end{array}$ \\
\hline $\begin{array}{l}\text { Accuracy of } \\
\text { self-assessment }\end{array}$ & $\begin{array}{l}\text { Disparity between } \\
\text { self-reported progress } \\
\text { and site visit team de- } \\
\text { termination (interval) }\end{array}$ & $\begin{array}{l}\text { Calculated difference between SVT } \\
\text { Assessment of Progress ( } 0-4 \text { ) and Self- } \\
\text { Reported Assessment of Progress ( } 0-4)\end{array}$ & Calculated \\
\hline
\end{tabular}


determination of progress. We are also interested in learning whether increased assessment progress has occurred over time, as the gradual implementation and enforcement of the standards presumes, and whether progress on assessment of student learning outcomes differs in any noticeable way on the basis of accreditation status at the time of review. The operational definitions of each of these conceptual variables are provided in Table 2 .

Our analysis in relation to research question 2 is organized into three general areas, corresponding to progress toward full assessment of all competencies, accuracy of self-reported progress on assessment, and implementation differences across the universal competencies areas.

Full assessment progress. As indicated earlier, assessment of student learning outcomes is a relatively recent addition to NASPAA standards. The assessment and reporting requirements of the standards are expected to phase in over time as programs develop the capacity to engage in this form of evaluation. COPRA's gradually increasing expectations for how many competencies a program has taken through a full assessment cycle reflect the underlying belief that it will take time for programs to engage in the process of defining competencies, gathering data, and then analyzing and using the data for strategic decisions. Programs in later cohorts have more time to adjust than those in earlier cohorts. Additionally, there is an implicit assumption that the sharing of collective knowledge and experience will further assist programs in later cohorts. Because programs seeking initial accreditation have complete control over when to enter the accreditation review cycle, whereas programs seeking reaccreditation are on a prescribed cycle and must submit a Self-Study Report, we also are interested in whether programs in the former group are engaging in full assessment more than those in the latter group are.

Using a chi-square test, we find no statistically significant relationship between cohort year and the full assessment progress. Even when the pilot year was removed from the analysis due to programs' disproportionate reporting of full assessment in that year, the relationship did not rise to the .05 level of statistical significance. Similarly, a chi-square analysis of the variables of accreditation status (initial accreditation or reaccreditation) and full assessment progress (collapsed into two categories of $0-3$ or $4-5$ competencies, assessed fully to ensure sufficient observations in each cell) indicates the lack of any statistically significant difference in the extent of full assessment progress between initial accreditation applicants and reaccreditation applicants. That is, since initial implementation of the standards and despite the rising expectations of COPRA, for the programs in this data set there has not been a measurable change in assessment progress over time, nor is there any noticeable difference in assessment progress among applicants for initial accreditation relative to reaccreditation.

\section{Self-reported vs. site visit determination of assess-} ment progress. In making its accreditation decisions, COPRA relies on both a program's Self-Study Report and the report prepared by the site visit team. In general, these are expected to reinforce one another, although site visit teams regularly report information-both positive and negative- that was not made clear in the Self-Study Report. The role of the site visit team is to be the "eyes and ears of COPRA"; they are to confirm the accuracy of a program's SSR, provide an independent assessment of each standard, and be particularly attentive to the items identified by COPRA in the Interim Report. A program's ability to accurately gauge and report its own progress on competency assessment may be compromised by its subjectivity and the felt pressure to portray the program in the most positive light in the SelfStudy Report. The site visit team, on the other hand, brings an objective, external perspective and may feel the pressure to be conservative in their estimates of program progress in their role as the eyes and ears of COPRA.

A simple correlation analysis between selfreported and site visit team assessments of progress on each of the universal competencies illustrates a moderately positive relationship. 
TABLE 3.

Self-Reported and Site Visit Team Reported Assessment Progress

\begin{tabular}{|l|c|c|}
\hline \multicolumn{1}{|c|}{ Competency } & $\begin{array}{c}\text { Self-reported in SSR, } \\
\text { excludes programs with no site visit } \\
\text { yet (mean score) }\end{array}$ & $\begin{array}{c}\text { SVT assessment } \\
\text { (mean score) }\end{array}$ \\
\hline 1. To Lead and Manage & 2.96 & 2.18 \\
\hline 2. Public Policy Process & 2.88 & 2.14 \\
\hline 3. Analyze, Synthesize,... & 3.36 & 2.46 \\
\hline 4. Public Service Perspective & 2.80 & 2.88 \\
\hline 5. Diverse and Changing & 2.77 & 2.92 \\
\hline Note. $n=55$ & & \\
\hline
\end{tabular}

The correlation coefficients $(r)$ ranged from 0.30 to 0.49 , suggesting that between $9 \%$ and $24 \%$ of the variation in one is associated with variation in the other. There is a positive relationship, albeit relatively weak, between selfreported progress on assessment and site visit team assessment of progress. Table 3 presents average progress scores for each of the five universal competencies as reported in Self-Study reports and in Site Visit Team reports for all programs for which data is available from both sources.

Paired $t$-tests on self-reported progress and site visit team progress show statistically significant differences in the means on all five competencies ( $p$-values are all significant at the .001 level). More specifically, the data show that programs consistently overestimate their progress on the first three universal competencies and understate their progress on Universal Competencies 4 and 5, as compared to the assessments of their site visit teams (see Table 3). This observation leads us logically to an examination of differences across the universal competencies.

\section{Differences across the universal competencies.}

Even as the expected number of universal competencies that a program should complete as part of a full four-part assessment cycle has been increased, the expectations for reporting have remained constant. Programs are required to report on only one universal competency as part of the Self-Study Report, and they are asked to identify which competency they have selected. As discussed earlier, in their review of Self-Study Reports from the 2010-11 and 2011-12 cohorts, Saint-Germain and Powell (2012) found a clear difference regarding which competencies were selected for reporting a full assessment cycle. Fifteen of the 29 programs $(52 \%)$ chose UC1 (to lead and manage in public governance) and 10 programs (34\%) selected UC3 (to analyze, synthesize, think critically, solve problems, and make decisions), whereas the other three universal competencies were selected by only one program each; a final program opted to report on all five competencies.

A closer examination of how programs chose to define those competencies during those initial years illustrated that the definitions for UC1 tended to focus on generic leadership and management and gave minimal attention to the aspect of public governance. Without the consideration of unique public aspects, both UC1 and UC3 can be seen as generic professional competencies rather than competencies specific to public service professions. In the absence of a particular emphasis on public governance, competencies for leadership and management are reminiscent of Gulick's (1936) classic POSDCORB model representing the generic skills of Planning, Organizing, Directing, Staffing, Coordinating, Reporting, and Budgeting. Similarly, analyzing, synthesizing, thinking critically, solving problems, and making decisions are competencies we would expect 
across many if not all professions. Generic professional competencies may be easier to define and measure, and/or there may be existing resources to draw upon from other professions to assist in this process. The other universal competencies are uniquely public in nature (i.e., public policy process, public service values, citizenry) and thus may be more challenging to define and measure. The Diversity competency may be among the most challenging to define and measure because it entails so-called soft skills or application of emotional intelligence. For these reasons, we expect that UC1 and UC3 will continue to be the most frequency selected for reporting in the Self-Study Report, that there will be a difference in the selfreported assessment of progress across the five universal competencies, and that the progress on UC1 and UC3 will exceed the progress on UC2, UC4, and UC5.

As illustrated in in Table 4, the most frequently selected competency over the study period is the one dealing with students' abilities to "analyze, synthesize, think critically, solve problems and make decisions" (UC3) followed by to "lead and manage in public governance"
(UC1). Many fewer programs have chosen to highlight their progress on "participate in and contribute to the policy process," "apply a public service perspective," or "communicate and interact productively with a diverse and changing workforce and citizenry."

Across all five competencies, the modal level of self-reported progress on assessment is 4, indicating that the most frequently reported level is full assessment. The median and mean scores show some finer distinctions (Table 5). The median scores of 4 for the first three universal competencies indicate that at least half of all programs report having completed a full assessment cycle for those competences, whereas the median score of 3 for UC4 and UC5 suggests less progress. The mean scores reveal additional nuances. The highest mean score is on the competency regarding analyzing, synthesizing, thinking critically, solving problems, and making decisions (UC3); the comparatively small standard deviation also indicates a greater concentration around that mean. The lowest mean scores (below 3.0) are for the competencies regarding applying a public service perspective and working with

TABLE 4.

Universal Competency Selected for Self-Study Report Full-Cycle Reporting

\begin{tabular}{|l|c|c|c|c|}
\hline \multicolumn{1}{|c}{$\begin{array}{c}\text { Competency } \\
\text { (abbreviated description) }\end{array}$} & $\begin{array}{c}\text { Number of } \\
\text { programs }\end{array}$ & Percentage & $\begin{array}{c}\text { Number of } \\
\text { programs } \\
\text { including multiple } \\
\text { competencies }\end{array}$ Percentage $^{2}$ \\
\hline 1. To Lead and Manage & 19 & $26 \%$ & 25 & $35 \%$ \\
\hline 2. Public Policy Process & 8 & $11 \%$ & 14 & $19 \%$ \\
\hline 3. Analyze, Synthesize,... & 27 & $38 \%$ & 33 & $46 \%$ \\
\hline 4. Public Service Perspective & 5 & $7 \%$ & 10 & $14 \%$ \\
\hline 5. Diverse and Changing & 7 & $10 \%$ & 13 & $18 \%$ \\
\hline Multiple Competencies & 6 & $8 \%$ & & \\
\hline
\end{tabular}

Notes.

1. Although not required to do so, several programs elected to report a full cycle of assessment for more than one competency. Of the six programs that chose to do so, five reported on all five universal competencies and one reported on the first three of the five.

2. The percentages in this column total more than $100 \%$ due to counting programs multiple times if they reported a full assessment cycle for multiple competencies. 
diverse and changing populations. All of this data should be considered in light of the earlier findings that programs consistently evaluate their progress on assessment higher than do their subsequent site visit teams.

Analysis of variance (ANOVA) illustrates a statistically significant difference in the selfreported progress level across the five universal competencies. The between group difference is statistically significant ( $p$-value is .04). There is a statistically significant difference in selfreported assessment progress between the five competencies. To better understand the nature of those differences, we examined paired relationships among the universal competencies. Table 6 provides the correlation coefficients among the self-reported progress on assessment of the five universal competencies. Correlations are moderate to strong among all competencies, although weakest correlations are between Universal Competency 3 (to analyze, synthesize, think critically, solve problems, and make decisions) and all others.

Paired $t$-tests among the self-reported progress levels for every combination of pairs of universal competencies indicates that the only statistically significant differences are between UC3 and each of the others. That is, the self-reported progress on UC3 is statistically significant when compared individually to that on UC1, on UC2, on UC4, and on UC5. All other combinations of pairs result in $p$-values that do not meet the 0.05 level of statistical significance. Put another way, between and among

TABLE 5.

Assessment Progress on the Universal Competencies

\begin{tabular}{|c|c|c|c|c|}
\hline \multirow[b]{2}{*}{ Competency } & \multicolumn{4}{|c|}{ Self-report in SSR, all programs $(n=91)$} \\
\hline & Mode & Median & Mean score & Standard deviation \\
\hline 1. To Lead and Manage & 4 & 4 & 3.03 & 1.29 \\
\hline 2. Public Policy Process & 4 & 4 & 3.00 & 1.30 \\
\hline 3. Analyze, Synthesize,... & 4 & 4 & 3.41 & 1.12 \\
\hline 4. Public Service Perspective & 4 & 3 & 2.88 & 1.31 \\
\hline 5. Diverse and Changing & 4 & 3 & 2.92 & 1.27 \\
\hline
\end{tabular}

TABLE 6.

Correlation Matrix of Self-Reported Progress on Universal Competencies

\begin{tabular}{|c|c|c|c|c|c|}
\hline \multicolumn{7}{c}{ UC1 } & UC2 & UC3 & UC4 & UC5 \\
\hline UC1 & 1.0 & & & \\
\hline UC2 & 0.71 & 1.0 & 1.0 & & \\
\hline UC3 & 0.43 & 0.41 & 0.51 & 1.0 & \\
\hline UC4 & 0.73 & 0.75 & 0.43 & 0.67 & 1.0 \\
\hline UC5 & 0.70 & 0.71 & & & \\
\hline
\end{tabular}

Note. $n=91$ 
UC1, UC2, UC4, and UC5, the self-reported progress levels are, statistically speaking, the same. Thus, although we might expect program progress to lag on assessment of competencies related to diversity, this exploratory analysis suggests that progress on the diversity competency is comparable to most of the other competencies. Only in UC3 - which addresses analytical, critical thinking, and decision-making skills-are programs demonstrating more confidence in their progress.
Diversity competency in relation to other diversity indicators. The third area of interest is represented by our final research question, which asks: To what extent and in what ways is progress on UC5 related to other aspects of diversity within a program? The premise for this question is that commitment to diversity can manifest itself in several ways and that we might expect to find relationships between these various measures of diversity commitment within a program. For this section of the analysis, we examine whether

TABLE 7.

Definitions of Additional Variables for Research Question 3

\begin{tabular}{|c|c|c|c|}
\hline Concept & Measure & Coding & Source \\
\hline $\begin{array}{l}\text { Minority-serving } \\
\text { institution } \\
\text { (MSI) status }\end{array}$ & $\begin{array}{l}\text { Whether the program } \\
\text { is housed within a MSI }\end{array}$ & $\begin{aligned} 0= & \text { not an MSI } \\
1= & \text { Hispanic-serving } \\
& \text { institution }(\mathrm{HSI}) \\
2= & \text { historically black college } \\
& \text { and university }(\mathrm{HBCU})\end{aligned}$ & $\begin{array}{l}\text { List compiled by } \\
\text { White House Initiative } \\
\text { on HBCUs, and } \\
\text { U.S. Department } \\
\text { of Education }\end{array}$ \\
\hline Faculty diversity & $\begin{array}{l}\text { Whether COPRA re- } \\
\text { quires program moni- } \\
\text { toring on Standard } 3.2\end{array}$ & $\begin{array}{l}0=\text { no monitoring } \\
1=\text { monitoring }\end{array}$ & NASPAA Data Center \\
\hline Student diversity & $\begin{array}{l}\text { Whether COPRA re- } \\
\text { quires program moni- } \\
\text { toring on Standard } 4.4\end{array}$ & $\begin{array}{l}0=\text { no monitoring } \\
1=\text { monitoring }\end{array}$ & NASPAA Data Center \\
\hline $\begin{array}{l}\text { Monitoring on } \\
\text { diversity-related } \\
\text { standards }\end{array}$ & $\begin{array}{l}\text { Index based on } \\
\text { faculty diversity } \\
\text { and student } \\
\text { diversity variables }\end{array}$ & $\begin{aligned} 0= & \text { no monitoring on } \\
& \text { either } 3.2 \text { or } 4.4 \\
1= & \text { monitoring on } 3.2 \text { or } 4.4 \\
2= & \text { monitoring on } 3.2 \text { and } 4.4\end{aligned}$ & Calculated \\
\hline Diversity in mission & $\begin{array}{l}\text { Whether the program } \\
\text { mission makes } \\
\text { reference to diversity, } \\
\text { cultural competence, } \\
\text { diverse teams, or } \\
\text { related values of } \\
\text { equity, equality } \\
\text { or justice }\end{array}$ & $\begin{aligned} 0= & \text { no mention of any } \\
& \text { diversity-related con- } \\
& \text { cepts in the program } \\
& \text { mission statement. } \\
1= & \text { reference to one or } \\
& \text { more diversity-related } \\
& \text { concepts in the mis- } \\
& \text { sion statement }\end{aligned}$ & $\begin{array}{l}\text { Content analysis of } \\
\text { mission as presented } \\
\text { in SSR, Standard } 1.0\end{array}$ \\
\hline $\begin{array}{l}\text { Breadth of } \\
\text { definition } \\
\text { of UC5 }\end{array}$ & $\begin{array}{l}\text { Extent to which } \\
\text { a program's UC5 } \\
\text { definition includes } \\
\text { multiple dimensions } \\
\text { of the typology }\end{array}$ & $\begin{array}{l}\text { Number of dimensions in } \\
\text { the definition of UC5: } \\
0=\text { none } \\
1=\text { one of the dimensions } \\
2=\text { two of the dimensions } \\
3=\text { all three dimensions }\end{array}$ & $\begin{array}{l}\text { Calculated } \\
\text { using typology } \\
\text { presented earlier }\end{array}$ \\
\hline $\begin{array}{l}\text { Depth of } \\
\text { definition } \\
\text { of UC5 }\end{array}$ & $\begin{array}{l}\text { The extent to which } \\
\text { a program's UC5 } \\
\text { definition includes } \\
\text { level } 2 \text { aspects of } \\
\text { the dimensions }\end{array}$ & $\begin{array}{l}\text { Aggregate score across } \\
\text { the three dimensions: } \\
\text { range } 0 \text { to } 6\end{array}$ & $\begin{array}{l}\text { Calculated } \\
\text { using typology } \\
\text { presented earlier }\end{array}$ \\
\hline
\end{tabular}


progress on UC5 is related to other program indicators of diversity examined in the accreditation review process, for example, references to diversity in the program mission, faculty diversity, student diversity, or institutional status as a minority-serving institution (MSI). For the purposes of this analysis, Table 7 lists and defines several additional variables.

Our overarching interest is to get a sense of whether programs that demonstrate commitment to diversity in other areas will report greater progress on UC5 than those programs that do not demonstrate commitment to diversity. We start by examining whether a program's status as an MSI translates into greater reference to diversity within a program mission and progress on UC5. Programs in the United States are classified as MSIs by virtue of their historical role in serving minority populations or by the proportion of their current student body. For our purposes, NASPAA member programs fall into one of two MSI categories as being either a Hispanic-serving institution (HSI) or a historically black college and university (HBCU). Of the 91 programs included in our analysis, 9 are classified as HSIs, 5 as HBCUs, and the remaining 77 are not MSIs. Due to the small numbers of HSIs and HBCUs, for the purposes of analysis, data for both are collapsed into a single category of MSI.

In the context of mission-based accreditation, the mission is presumed to be a guiding force in all program decisions and actions. It is thus reasonable to expect and appropriate to examine whether programs that explicitly reference diversity in their missions have prioritized the diversity competency for assessment and have included more comprehensive definitions of the diversity competency in comparison to those program which lack such references in their mission. We are also interested in whether a program's mission statement - more precisely, whether the mission statement makes reference to diversity - is associated with progress on UC5.

This research first required an analysis of mission statements. We conducted a content analy- sis of program missions provided in the SelfStudy Reports and looked for words or phrases that corresponded with any of the components of Universal Competency 5. Specifically, we sought references to diversity, difference, or culture; to the values of social equity, fairness, or social justice; or to those of teamwork, collaboration, and communication across differences, as referenced earlier regarding the body of literature on cultural competency. Roughly half (48\%) of all programs include some mention of diversity in the mission per our criteria, and the remaining $52 \%$ do not. The extent of reference to any of these concepts in the program mission varies considerably in depth and specificity, as do mission statements generally. Some program missions include a simple reference to preparing a diverse group of students, respect for diversity, or the value of equity, whereas others are more tailored to the unique focus of the program (e.g., "alleviate poverty, values of sensitivity and justice, compassion for marginalized communities," "reducing disparities throughout the world," or "serve our communities, especially the most vulnerable among us").

Finally, we examined a program's status on faculty and student diversity based on whether COPRA is monitoring the program in its annual maintenance reports for concerns in one or both of those areas (Standards 3.2 and 4.4, respectively). COPRA monitoring serves as proxy measure for diversity efforts and provides us with a more comparable variable across programs.

All the variables of diversity commitment are measured at a categorical level (MSI and mission variables are nominal; the monitoring and progress variables are ordinal), so the analysis was conducted in the form of chisquare tests. For the purposes of this analysis, the progress variable (self-reported implementation of a full assessment cycle on UC5) was collapsed from scores ranging from 0 to 4 to three categories of below, at, or above the mean score for progress on that competency to reflect a relative measure of progress in comparison to other programs. 
Not surprisingly, public affairs programs within MSIs are more likely to explicitly reference in their mission statements issues such as serving diverse communities, increasing the demographic representativeness of government, promoting cultural competence, and advancing social equity than programs that are not within MSIs $(p=.05)$. However, we found no statistically significant relationships between the other measures of diversity commitment and selfreported progress on the diversity competency.

Returning to our typology of diversity dimensions presented earlier in the paper, we also examine whether a program's mission, specifically whether it includes reference to diversity, is related to the depth and breadth of the definition of UC5. For programs that identify diversity in their program mission, we expect more of the dimensions to be included and at a higher level; however, this relationship is not evident in the data. The results from chi-square analysis illustrate that programs with references to diversity in the mission are no more likely than those without such references to incorporate multiple dimensions or higher-level expectations in their definitions of UC5.

\section{SIGNIFICANCE OF FINDINGS AND IMPLICATIONS}

As explained early in the paper, an exploratory analysis conducted during the early stages of the standards implementation process has inherent limitations and naturally generates as many questions as answers. Even with those limitations, our research produced some interesting and sometimes counterintuitive findings that have implications for COPRA, for leadership at NASPAA, for program directors, and for scholars interested in furthering this line of research.

\section{Implications for COPRA and NASPAA Leadership}

The lack of noticeable progress in competency assessment over time suggests the need to continue a slow pace in implementing full assessment. It is taking time for programs to gear up and do this work, especially when they are attempting to seriously integrate competency assessment into existing program management strategies. It is important to remember that while COPRA members, site visitors, and NASPAA staff who support accreditation have multiple years of experience using the competency-based standards, each program undergoing review during the years encompassed by our research are using the standards for selfassessment for the first time. This will continue to be the case until the completion of the 2017-18 cohort year. COPRA acknowledged the continuing need for a slow pace of implementation during and following the 2013 NASPAA annual conference by issuing a policy statement continuing the phase-in of conformance expectations; this research provides evidence grounded in systematic analysis of the data to reinforce their decision.

The research findings also suggest the need for a continued dialogue and more training on how to craft competency definitions that are more explicitly linked to a program's mission. Although the intent is to have competency definitions that are grounded in and tailored to the program mission, very few programs are doing that for UC5 at this stage. It appears that the sample definitions provided in the instructions for preparing a Self-Study Report may actually be impeding this process and encouraging programs to adopt common rather than uniquely tailored statements.

The significant and persistent gap between selfreported and site visit assessments raises the question, why are the assessments so different when both parties go through similar training? Does each party have unrealistic expectations of the other? Does self-selection of site visitors contribute to the knowledge and expectations gap? It is often presumed that the site visit members, and especially those in the chair role, have an advanced understanding of best practices in student learning assessment and the requirements for meeting accreditation standards. It may be reasonable to assume that the teams have a stronger understanding of best practices in educational assessment than do the academics at programs, who may not have selfselected to be peer reviewers for this process. 
To improve consistency in the conversation around competencies, COPRA is reportedly working to build overall understanding of assessment best practices and the expectations for accreditation. In part, COPRA has indicated it is working to develop more meaningful rubrics to be used by teams and the review commission itself to improve consistency in assessment discussions. Given the findings here, efforts to reduce the disparity in assessment between reviewed programs and peer review teams appear to be a needed initiative.

\section{Implications for Program Directors}

Our findings demonstrate that programs are relying heavily on the sample competency definitions developed by a task force and included as an appendix in COPRA's Self-Study Instructions. We also document that programs are largely choosing to focus on communication and diversity at a general level of knowledge and basic skills, and a smaller proportion are emphasizing laws and policies or taking any of these dimensions to a higher cognitive level requiring application and demonstration of advanced skills. The typology we developed, based on a content analysis of UC5 definitions, should provide program directors with a framework for thinking about and defining this competency in the context of their own mission.

Our research also suggests that a confounding factor appears to be the generic nature of some mission statements and that program directors may want to lead their faculty in a discussion of the relative merits and limitations of a generic mission statement. Under the current accreditation process, programs are free to craft a more generic mission statement, if appropriate for their goals and the needs of their stakeholders, and many have chosen to do so. However, this type of broad statement is vexing in this analysis due to the difficulty of connecting any competency to a broad mission statement championing effectiveness in the public sector. Likewise, generic missions have proven to be a challenge to the entire assessment framework both in the context of our research and for the work of COPRA. As a result, supplemental goal statements or operational strategies are often treated as if they are "mission" for purposes of analysis. However, it is not always clear when such treatment is appropriate. Programs are encouraged to think carefully about their mission statements as they relate to other aspects of the accreditation review, specifically to definition of universal competencies.

\section{Implications for Future Research}

Our exploratory analysis was limited to an examination of competency definitions and reported progress on assessment. It is too early to conduct analysis or draw any conclusions about the sophistication of the measures or processes used to evaluate UC5 or any of the other universal competencies. The competency definitions provide an important window into the achievement goals of programs. However, the depth of penetration into curriculum and student learning requires a more analytical look into the level of assessment, the tools and processes used, the extent to which stakeholders are meaningfully engaged in assessment, and the integration of evidence into the mission process of the program. All of these topics would provide additional insight and strengthen the development of individual competencies.

Regarding implementation of competency assessment, some critical time threshold may yet need to be reached, after which more overall progress will be observed. Many programs up for reaccreditation appear to be engaging in substantial strategic planning processes before their prescribed accreditation year, as opposed to simply enhancing and updating existing assessment methods. Done well and with appropriate stakeholder engagement, a more robust process can slow progress in the short term, although it can potentially add more meaning over time. Program administrative capacity to plan strategically, implement new tools, and collect data may limit the implementation of new assessment strategies. Programs may also be stuck in early phases of implementation due to a scarcity of best practice examples in the field or perhaps in response to lenient expectations communicated by the review commission in the first few years of review. 
Additionally, it may be too early in the implementation process of new accreditation standards to see strong connections between programmatic mission and competency definitions. The lack of connection between commitment to cultural competency in the mission statement and implementation of a cultural competency definition at higher cognitive levels is surprising. It would be interesting to see further analysis comparing competency definitions and the relationship to mission in other competency domains. Although missions should be the guiding force, they are also dynamic and subject to revision. Most likely, competency definitions have been established more recently (in preparation for accreditation) than the mission statement of the program, and perhaps programs have not yet had time to revisit their missions in light of the competency discussions. Given that the accreditation process requires programs to use assessment evidence to revise the mission as necessary, an analysis after all programs have been through the new process at least once might yield stronger connections.

Additionally, our research was intentionally exploratory in nature and did not postulate or test any causal hypotheses. Future research should attempt to explain, not simply describe, differences in assessment progress across programs.

\section{Broader Implications and Final Reflections}

Collectively as a field-certainly within NASPAA committees, but also within the broader professional network of NASPAA — we need to discuss and reach some consensus about our expectations as they relate to cultural competencies. For example, we need to ask ourselves: To what extent are any or all of the three dimensions of the cultural competency typology essential? Are any or all of them necessary for all programs seeking NASPPA accreditation, or is this determination entirely mission based? To what extent should the competency definitions be explicitly linked to mission statements? How are these links to be made for programs with relatively generic missions? If programs can demonstrate progress on the definition and assessment of UC5 and are able to document that their students are graduating with strong cultural competencies, can that compensate for lack of progress on the traditional input measures of faculty and student diversity in the accreditation review process? How can we better align understandings and expectations to minimize the disparities between program self-assessments and the evaluations of site visit teams?

As mentioned at the beginning of the paper, the standards revision undertaken in 2009 also opened NASPAA accreditation to programs outside of the United States. As the number of accredited international programs grows, it will be important and interesting to examine how international programs are defining diversity and diversity-related competencies. This will be an important component of advancing NASPAA's understanding of the global applicability of the accreditation competency standards as well as those regarding faculty and student diversity.

The ultimate goal of the assessment process is to ensure that graduates have the skills they need to make a positive difference in public service. Proving that they do, and improving when they do not, is the ongoing practical challenge. Assuming these definitions and goals are realized over time, it remains to be seen what we as a profession will be able to say about what our graduates will be able to do and contribute in terms of communicating and interacting productively with a diverse and changing workforce.

\section{REFERENCES}

Bonilla, J. F., Lindeman, L. A., \& Taylor, N. R. (2012). Educating for and assessing cultural competence. In K. Norman-Major \& S. Gooden (Eds.), Cultural competency for public administration (pp. 294-309). Armonk, NY: M.E. Sharpe.

Gulick, L. 1936. Notes on the theory of organization. In L. Gulick \& L. Urwick (Eds.), Papers on the science of administration (pp. 3-35). New York: Institute of Public Administration. 
Lewis, P. H., Lewis, A. N., \& Williams, F. D. (2012). Cultural competency in public administration programs. In K. Norman-Major \& S. Gooden (Eds.), Cultural competency for public administration (pp. 244-264). Armonk, NY: M.E. Sharpe.

Mizrav, E. (2012). NASPAA annual accreditation data report: 2011-12. Washington, DC: NASPAA.

Norman-Major, K. (2011). Balancing the four E's; or can we achieve equity for social equity in public administration? Journal of Public Affairs Education, 17(2), 233-252.

(2012). Cultural competency across the master's in public administration curriculum. In K. Norman-Major \& S. Gooden (Eds.), Cultural competency for public administration (pp. 310-330). Armonk, NY: M.E. Sharpe.

Page, S. E. (2007). The difference: How the power of diversity creates better groups, firms, schools and societies. Princeton, NJ: Princeton University Press.

Powell, D., Piskulich, M., \& Saint-Germain, M. (2011, October 1). Expectations for student learning outcomes assessment for NASPAA-COPRA accreditation. NASPAA White Paper. Washington, DC: NASPAA.

Primo, N. (2013). NASPAA diversity report 2013: over a decade in review. Washington, DC: NASPAA.

Rice, M. F. (2007). Promoting cultural competency in public administration and public service delivery: Utilizing self-assessment tools and performance measures. Journal of Public Affairs Education, 13(1), 41-57.

Rice, M. F., \& Matthews, A. L. (2012). A new kind of public service professional: Possessing cultural competency awareness, knowledge, and skills. In K. Norman-Major \& S. Gooden (Eds.), Cultural competency for public administration (pp. pp. 19-31). Armonk, NY: M.E. Sharpe.

Rubaii, N., \& Calarusse, C. (2012). The evolution of cultural competency as a standard for accreditation: The past, present and future role of NASPAA accreditation. In K. Norman-Major \& S. Gooden (Eds.), Cultural competency for public administration (pp. 219-243). Armonk, NY: M.E. Sharpe.

Saint-Germain, M., \& Powell, D. (2012, February). NASPAA competencies task force analysis of Standard 5 in 2011 self-studies for accreditation. NASPAA White Paper. Washington, DC: NASPAA.
United States Department of Education. (2012). National Center for Education Statistics. The condition of education 2010. Retrieved from http://nces.ed. gov/programs/coe/

White, S. (2004). Multicultural MPA curriculum: Are we preparing culturally competent public administrators? Journal of Public Affairs Education, 10(2), 111-123.

Wyatt-Nichol, H., Brown, S., \& Haynes, W. (2011). Social class and socioeconomic status: Relevance and inclusion in MPA-MPP programs. Journal of Public Affairs Education, 17(2), 187-208.

\section{ABOUT THE AUTHORS}

Nadia Rubaii, PhD, is associate professor of public administration in the College of Community and Public Affairs at Binghamton University, State University of New York. Her research focuses on issues of diversity, cultural competency, and local government policies for the effective integration of immigrants in communities. More recently, her focus has been on public administration education in Latin America in relation to international accreditation as part of her appointment as a Fulbright Core Scholar in Colombia. She has previously served as NASPAA president and chair of COPRA and remains active in many NASPAA committees.

Crystal Calarusse, MPP, is the chief accreditation officer at NASPAA, where she oversees quality assurance for graduate degrees in public service. Previously, she managed the NASPAA Standards 2009 initiative, which introduced to NASPAA competency-based educational assessment based on public service values and transparency. She is responsible for the global expansion of NASPAA's accreditation services and serves on the executive board of the Association of Specialized and Professional Accreditors (ASPA). 